\title{
Wireless Broadband for Municipal Police: Evaluating Clearance Times of Calls for Service
}

\author{
Jeremy G. Carter, Ph.D. \\ Assistant Professor \\ School of Public and Environmental Affairs \\ Indiana University - Purdue University Indianapolis \\ 801 W. Michigan Street \\ Indianapolis, IN 46202 \\ P: (317) 274-4170 \\ carterjg@iupui.edu \\ Eric Grommon Ph.D. \\ Assistant Professor \\ School of Public and Environmental Affairs \\ Indiana University - Purdue University Indianapolis \\ 801 W. Michigan Street \\ Indianapolis, IN 46202 \\ P: (317) 278-9481 \\ egrommon@iupui.edu
}

\begin{abstract}
Though research has explored impacts of mobile computing and information technology on police operations, the literature lacks exploration of large bandwidth data sharing technologies which enhance the utility of mobile computing terminals. As part of a federally-funded project, the present study employs a longitudinal pre/post design utilizing seven years of computer-aided dispatch data from a medium-sized municipal police department in the New England region. Pooled time series analyses are employed to examine the effect of wireless broadband implementation on clearance time of calls for service. Findings offer tentative support that clearance times for service calls decreased with the implementation of a wireless broadband network. Implementation did not appear to generate differential effects in areas that had experienced past challenges with cellular communication signals. Implications are provided, with emphasis on the development of additional knowledge on technological evaluations.
\end{abstract}

\section{Keywords:}

Wireless broadband, Information technology, Mobile computing, Call clearance

\section{Citation:}

Carter, J. G. \& Grommon, E. (2014). Wireless broadband for municipal police: Evaluating clearance times of calls for service. Police Quarterly. Advance online publication. DOI: 10.1177/1098611114533553. 


\section{Wireless Broadband for Municipal Police: Evaluating Clearance Times of Calls for Service ${ }^{1}$}

\section{Introduction}

Police departments are becoming increasingly sophisticated through the use of emerging technologies. A nationally representative sample of local police departments in the United States has suggested that most departments use computerized information systems to access and maintain records, dispatch fleets, assist with investigations, share information, and generate data for resource allocations (Reaves, 2010). Approximately 90 percent of officers use in-field computers or computer terminals. Field functions primarily support report writing and/or communications as well as provide access to vehicle, driving, calls-for-service, and criminal records. Six out of 10 police departments also electronically transmit field reports to headquartered information systems. From the year 2003 to 2007, the percent of departments using electronic transmissions increased by 58 percent (Reaves, 2010).

As technology continues to expand and advance, there are calls to integrate computerized information to improve intra- and inter-agency communications (Carter \& Carter, 2009a; Ratcliffe, 2008). It is implicitly assumed that integration efforts will enhance the efficiency and effectiveness of a variety of police operations (Koper et al., 2009). In order to accomplish these objectives and realize the benefit potential, police departments must possess adequate communication system infrastructures. Recent momentum towards the development of wireless broadband networks for public safety is one approach to develop a sustainable and effective infrastructure. Though commonly accepted and implemented by private business, public safety

\footnotetext{
${ }^{1}$ This research is based on data from the National Institute of Justice award number 2010-IJ-CX-K023. The opinions, findings, conclusions, and recommendations expressed in this report are those of the authors and do not necessarily reflect those of the U.S. Department of Justice, Office of Justice Programs, National Institute of Justice. The authors have no vested interests in commercial communication technology products, processes, or services.
} 
organizations have traditionally been slow to keep pace with evolutions in digital communications. Resource limitations coupled with a lack of independent evaluation of such technologies have contributed to this shortcoming.

\section{Purpose of the Study}

Recently, a medium-sized municipality in the New England region of the U.S. was able to utilize a public-private partnership to implement a $4.9 \mathrm{GHz}$ wireless broadband network for public safety while simultaneously bringing this digital communication to local businesses and citizens. It is important to note the design of the system as it differs from commercial cellular data access. The $4.9 \mathrm{GHz}$ broadband network is a mesh network consisting of 350 wireless nodes (wireless transmitter access points) that are physically installed throughout the approximately seven-square mile municipality. Rather than relying on cellular signal strength, the wireless capability within each patrol vehicle constantly scans for the strongest signal available from the node closest to the vehicle at a given time. At any point during patrol, officers are connected to the strongest wireless broadband signal available in their location.

The decision to procure this infrastructure was three-fold. First, the department had relied on commercial cellular coverage to provide digital communications to patrol vehicles. Approximately one third of the patrol sectors suffered from poor signal strength due to geographic topography and building structures. Weak signal access led to redundancies in failed report submission and task completion. Officers would complain that as they attempted to complete tasks that relied on data signals, their work would be lost and they would have to start from the beginning of the task. Thus, the time to process and clear calls for service was suffering. Second, a large-bandwidth wireless network was believed to improve time savings on behalf of 
officers completing tasks while on patrol within their assigned sectors. Lastly, the migration to a wireless broadband network would allow for local business, citizens, and other public safety (i.e. fire and medical response) to access ubiquitous wireless signals throughout the municipality. The current research is intended to explore the effect this wireless broadband network has on the patrol operations of one medium-sized municipal police department. In addition, this research identifies areas for informing future evaluation research on the emerging importance of wireless broadband technology for public safety. There is a lack of scientifically informed and independent knowledge with respect to how a large-bandwidth wireless capability may influence law enforcement's daily operations. ${ }^{2}$ This research seeks to establish an empirical foundation for wireless broadband and large bandwidth digital communications research within policing.

Identifying and utilizing appropriate data for the evaluation of police technologies generally (Nunn \& Quinet, 2002) and broadband specifically (U.S Government Accountability Office, 2012) has been a significant obstacle for researchers. To this point, the academic knowledge base has been unable to maintain pace with emerging technologies within the field of policing. Extant literature has examined police information technology and mobile computing, yet there is a dramatic research shortcoming with regard to bandwidth technologies upon which digital data communications rely. Though this study is an explorative evaluation of wireless broadband and police operations, both the academic literature and the professional personnel tasked with technology procurement and decision making are in need of independent information related to this emerging capability.

\footnotetext{
${ }^{2}$ Available research to date on the performance capability and potential impacts of large bandwidth data communications is provided by private sector vendors which provide services to public safety agencies. This is the primary source of information available to procurement officials when making these costly decisions, despite the obvious conflict of interest involved with vendor-driven research on performance and capability.
} 


\section{Background and Context}

In a 2012 study of 216 agencies across the U.S., the Police Executive Research Forum (PERF) assessed the technological needs of law enforcement which would improve police operations and specifically noted the integration of information technology is paramount. As police patrol is a resource-intensive task (both personnel time and vehicle costs) and accounts for the majority of police time and responsibility (Wilson \& Weiss, 2012), the allocation of these resources can be improved by integrating technology into calls for service and patrol functions (Kennedy et al., 2011) which would allow agencies to devote additional resources to crime prevention strategies. Contemporary policing strategies such as problem-orientated policing, community-orientated policing, and intelligence-led policing now encourage police to make greater use of the data they routinely collect, and to be more analytic with regards to the data they utilize for tactical and strategic decision making (Carter \& Carter, 2009b; Chermak et al., 2013; Goldstein, 2003; Nunn \& Quinet, 2002). In order to fully embrace these problem-solving and preventative strategies, police are encouraged to collect data from a wide variety of sources of information, such as community members or organizations. Moreover, police are also encouraged to disseminate this new information to external organizations as these external stakeholders will be increasingly responsible for assisting police in identifying problems and developing solutions for dealing with them (e.g., partnering with state and federal agencies as well as community and private sector organizations). Since these strategies move beyond the limited information police routinely collect, adjustments to information systems within departments will become necessary as police shift their focus from individual calls for service to community problems, concerns, and threats. 
During an evaluation of Chicago Police Department's Citizen and Law Enforcement Analysis and Reporting system, a member of the department explained the bandwidth issue facing Chicago and many police departments across the country, noting that “...home dial-up modems are 56K. What we're dealing with is only 9K, and the pipe is small” (Skogan et al., 2003, p. 15). A similar obstacle faced the Rockford, Illinois Police Department (RPD) where officers were relegated to manual report writing in the field which was then turned over to data entry personnel to input the reports into the records management system. It was found that the data entry system would only allow enough space for a summary report rather than the report in its entirety - leaving important details and information solely available from the original hard copy and subjecting report information to second-hand interpretation (Sprint, 2007). For RPD personnel, time was wasted as report writing was duplicated by multiple personnel, valuable information was not available to enhance the effectiveness of officer tasks, and records were subsequently incomplete. The current Presidential administration is investing in an initiative to establish a nationwide wireless broadband network for public safety. In the report published by the White House (2011) that outlines this initiative, former Los Angeles, California chief of police William Bratton noted:

"An effective broadband network could provide officers with an immediate, digital snapshot... It would give them the suspect's address, prior arrest history, and other critical details. The officer would be able to take electronic fingerprints at the scene and compare them instantaneously with those in local, state, and federal databases” (p. 10).

Specifically this report noted that a nationwide wireless broadband capability would result in "ultimate time savings" for officers on the streets (p.11). 


\section{Digital Communications to Enhance Police Operations}

Integrating technology into law enforcement operations has become commonplace in the last two decades. Driven primarily by a scarcity of operational resources for police as well as more feasible costs for acquiring and maintaining technology have brought this movement to the forefront. Also not to be overlooked was the increase in post-September 11, 2001 federal grant programs for technology advancements in public safety that lacked any component of rigorous scientific evaluation following what technology was procured and how it was deployed to impact operations (Taylor \& Russell, 2012). In broad terms, the implementation of new technology has enhanced the productivity of law enforcement agencies by facilitating information sharing within and across departments, easing communication between law enforcement and the public for purposes of service and feedback, and enabling officers to identify and target crime problems more effectively (Colvin \& Goh, 2005; Maguire \& King, 2004).

Advances in computing have improved the ways law enforcement store, utilize, and disseminate data and information (Nunn, 2001). These advances have helped to translate conceptual policing philosophies such as problem-oriented policing and intelligence-led policing into practice - making law enforcement more efficient in the prevention and reduction of crimes, threats, and problems (Braga \&Weisburd, 2006). Scholars have found mixed results with respect to technological advances and police operations; ranging from improved productivity and efficiency (Colvin \&Goh, 2005) to less efficient (Manning, 2001) and no observed impacts on production (Nunn \&Quinet, 2002). Furthermore, technological advances in policing have also served as a catalyst to restructure police forces (Maguire \&King, 2004). The presence of computer technology among U.S. police agencies is abundant. According to Roberts (2011), who examined data from the 2007 Law Enforcement Management and Administrative Survey 
(LEMAS), the vast majority of agencies included in the survey reported using computers for a variety of law enforcement functions ranging from incident reporting to accessing individuals’ criminal history information.

Despite this overwhelming presence of digital computing among American law enforcement, to date there has been very little research specifically exploring the mechanism that allows for the potential of these technologies to be maximized - the technology of largebandwidth data communication. To develop an understanding of the potential operational effects associated with wireless broadband, it is necessary to consult research on information technology and mobile computing. These are two key components enabled by wireless broadband infrastructure.

\section{Information Technology}

Though evidence has been mixed, studies have indicated information technology systems have a positive impact on police operations. Early research on computer information management found detectives were able to access information easier and faster as they did not have to travel to different places to locate records while also having constant access to information at any time of day (Harper, 1991). In one of the most comprehensive studies of police time and information technology, Chan (2001) employed a representative non-random survey of 506 officers, completed 23 interviews with senior-level police and information technology specialists, conducted 11 focus groups with 106 participants including officers, detectives, intelligence officers, supervisors, and information management personnel, and documented over 30 hours of ride along observations across eight shifts in an attempt to examine the impact information technology had on police operations. 
The results indicated that police officers spent, on average, three hours and thirty seven minutes per eight hour shift using computers for administrative tasks. With respect to respondents' perceptions of the effectiveness and efficiency of information technology, 72 percent thought it made a great difference to police work while 26 percent thought it made little difference. More specifically, respondents indicated that information technology allowed them to work more effectively (79\%), made work easier (66\%), and helped them access information police needed to do work properly (59\%). Further results indicated that new information technology positively influences technology literacy among the majority (75\%) of respondents. To this point, it seems officer efficiency with technology is improved upon with the adoption of new technology. It remains unclear whether this may be the result of simply better technology hardware and user interface software that makes interaction with the technology easier or more intuitive, or that officers may become more efficient with technology through exposure and increased use of technologies as they are deployed. It seems reasonable to assume that, in general, improvements in the technology itself can lead to more efficient officer use of that technology - such as implementing wireless broadband to enhance the utility of mobile computing terminals.

\section{Mobile Computing Terminals (MCTs)}

Agrawal et al. (2003) utilized survey data of 153 patrol officers who employed mobile computing to study the impacts of mobile computing terminals on police operations. Of primary interest was how mobile computing terminals have improved critical factors that affect the work environment of officers. The researchers examined officers utilizing mobile terminals within patrol cars to conduct license plate and driver's license checks. The results indicated that such 
requests were sent through the departmental server to the state headquarters and the details of the vehicle were retrieved in roughly 20 seconds without having to route requests through the control center. Perhaps the most impressive finding from this study was that time saved by officers in conducting plate checks, issuing summons, and executing warrants of arrest as a result of utilizing MCTs was equivalent to the work performed by approximately 10 percent of the officer work force. Moreover, it was found that officers felt safer in neighborhoods in which there was perceived danger because they were able to quickly gather information on dangerous elements in the area whereas before officers had to rely on their personal knowledge.

A recent study by Lindsay et al. (2013) examined police acceptance of mobile information technologies across five agencies in the United Kingdom. In brief, their study noted that common factors related to officer acceptance of mobile technologies were the reliability and functionality of the device as well as the efficiency by which officers could use the technology. These findings indicate a utilitarian approach for integrating technology within police departments - that officers are primarily concerned with operational impacts. Using a random survey of 100 members of a medium-sized police agency in Arizona, Ioimo and Aronson (2004) conducted a similar, but more comprehensive, study of police mobile computing. To more directly measure the impact of MCTs within the context of police officers and field reporting, the researchers employed specific field computing items gleaned from previous research on technology at the individual level. These items asked officers if MCTs allow them to complete their tasks with more speed, quality, ease, control, (Davis, 1989; Moore \&Benbasat, 1992; Seddon \& Kiew, 1995) and less error (Leonard-Barton \& Deschamps, 1988) while also asking respondents to directly indicate how MCTs affected the effectiveness, performance, and productivity of their tasks (Davis, 1989; Moore \& Benbasat, 1992; Seddon \& Kiew, 1995). 
Generally, their study found statistical support indicating that inquiries to local, state, and national criminal information databases increased with the implementation of mobile computing. This study also found that field officers recognized the potential benefits mobile computing afforded them. However, field officers also reported that the amount of time required for completing reports increased with the implementation of field mobile computing. This is an important unintended consequence of mobile computing and appears to be a product of increased reporting fields. Findings also indicated that administrators, detectives, and records management personnel all experienced statistically significant improvements in the tasks they performed directly resulting from the implementation of mobile computing (Ioimo \& Aronson, 2004). More specifically, the study indicated increases in the number of arrests and inquiries into criminal information systems; lending insights that investigators and detectives were able to better access and manage information as a result of officers having to use field computing for reporting purposes.

\section{Enhancing MCTs through Wireless Communications}

Improved efficiency of processes while retaining or improving effective outcomes is at the heart of the mobile computing and information technology movement. However, though MCTs alone have shown a great deal of promise for improving police operations, their capabilities are enhanced through the use of data sharing via high-speed digital communications. Garicano and Heaton (2010) noted in their study of police departments from 1987-2003 that investments in information technology yielded best results in productivity when complemented with other organizational and management practices. Specifically, their study found an increase in data-related productivity to enhance programs such as CompStat. The collection, sharing, and 
querying of data within a police department to enhance information technology and mobile computing relies on a bandwidth capable of transmitting such data on a reliable basis. Webb (2004) noted the data speeds offered by wireless broadband allow officers to complete all necessary tasks remotely from the patrol car; "To replicate the office environment in the field requires broadband rates in excess of one megabyte per second. This speed allows an officer to access information quickly and do all paperwork in the patrol car. Broadband also enables voice and real-time video to be streamed to and from the patrol car. Officers can pull up feeds from fixed cameras and see real-time video while supervisors or dispatchers can see and hear what is happening in the vicinity of other units” (p. 28).

To achieve these desired digital communications, the use of cellular-based wireless communications is becoming more prevalent within police patrol vehicles (Argawal et al., 2003; Hampton \& Langham, 2005). Providers of commercial cellular service partner with public safety departments to provide service at a price deemed reasonable for those agencies. Commercial services often present agencies with a convenient and affordable upgrade path from lower bandwidth resources. However, commercial cellular network connection speeds, and connection availability, are both contingent upon the proximity of end users in relation to cellular towers. Tower deployment determines network coverage (i.e., network density) and network design choices often result in areas with no (or weak) coverage and lower net capacity near the edge of a given cell site coverage area. Devices operating in fringe locations often cannot reliably communicate with the network to support large bandwidth data (Sharma \& Jain, 2010) or users experience dead spots where service coverage is unavailable. Within areas dominated by tall buildings, mountains, or other large physical obstacles that interfere with radio communication waves, signal strength can also be significantly reduced (Chandra et al., 2011; Lia et al., 2008). 
Difficulties associated with terrain, and their impact on coverage and interoperability are not new to policing. Geographic terrain has always presented a constant challenge for radio communications (Taylor et al., 1998) and emergency call clearance efforts (Chenoweth \& Clarke, 2010).

One solution to resolve communication shortcomings experienced by commercial network users, to include wireless network coverage limitations, is through the implementation of alternative wireless technology. Wireless broadband systems present one such alternative and networks based on wireless technology can be designed to fill jurisdiction-specific coverage gaps and provide stronger, more consistent signal strengths (Amaldi et al., 2008). These networks can often be designed to provide large bandwidth capabilities across diverse terrains through the utilization of mesh networks (Marina et al., 2010). With respect to the contemporary demands of police personnel, such broadband systems and the bandwidths they provide have become critical to agency operations. In a case study of the 2007 bridge collapse in Minneapolis, Minnesota, a municipal wireless network enabled police to set up a command center in a parking lot near the site of the collapse. The study noted that “...this network had to be fast and robust enough to handle large, data-intensive geographical information services (GIS) maps...there is no way they could have downloaded or worked on all those heavy GIS maps, big bandwidth users, on a cellular network” (ENCOM Wireless, 2010, p. 35).

In sum, the literature has explored how information technology and mobile computing systems have influenced organizational operations of police departments. The review of this literature has come to the general conclusion that impacts of information technology and mobile computing vary and evidence to demonstrate a return on their investment is needed. In addition, the current literature lacks knowledge with respect to the widely recognized demand for wireless 
broadband within police patrol vehicles to enhance the utility of mobile technologies. A $4.9 \mathrm{GHz}$ mesh wireless broadband network was implemented in a medium-sized municipal police department in the New England region with the intent to improve wireless data access across patrol sectors under the belief that, among many operational benefits, the time efficiency to clear calls for service would improve. The present research seeks to explore this anticipated benefit. By improving the wireless data access in patrol vehicles located within patrol sectors, officers should access information needed to process a call for service more efficiently. Such an improvement should be observable across patrol sectors that previously suffered from poor commercial cellular coverage that now benefit from wireless broadband access as these patrol units are likely to access needed information more quickly to process calls for service.

\section{Methods}

\section{City of Study Profile}

The city for the current research is approximately 6.8 square miles, has a population of 58,732 with a median household income of $\$ 92,451$ as compared to a national average of \$51,017 (U.S. Census Bureau, 2012). The police department has 140 sworn officers, two information technology officers, one analyst, 16 full-time civilian dispatch, and 24 full-time civilian support staff. Approximately $60 \%$ of sworn officers have earned advanced degrees beyond a bachelor's degree. The majority of crime occurrences in the city are larceny, burglary, and assault while the most frequent types of calls handled by the police are building checks, medical emergencies, traffic, and alarms. Table 1 provides an illustration of the city as compared to areas of similar size in the United States. 
[ Table 1 approximately here ]

\section{Public-Private Partnership Business Model}

A unique business model was used to deploy a wireless broadband network for the police department and city involved in this study. The police department was soliciting proposals for a wireless vendor to provide a wireless broadband system to resolve issues with commercial cellular coverage and poor signal strength. A consumer market study conducted by the wireless vendor whose proposal was selected by the study city indicated significant demand for wireless services among residents. In exchange for access to residents to facilitate sales of wireless subscription services, the police department would receive a dedicated wireless broadband network - including necessary hardware for the build out - completely free of charge. Revenues generated from service subscription fees covered the vendor's construction costs, ongoing maintenance, and sustained the network for the police department. Residential and commercial subscriptions were available for \$20 per month and enhanced high speed commercial offerings for $\$ 40$ to $\$ 300$ per month. Wireless community hotspots in popular commercial districts and public parks were created and made available to all residents for a limited window of time per day. In addition, locations that qualified as public housing were given free access hot spots.

\section{Data}

The driving force behind adopting wireless broadband data communications is to allow officers who are operating within their assigned geographic patrol sectors to have access to the exact same information in their patrol vehicle that they would have if they were sitting at a desktop within the department. The benefit of such information access is that during real-time events, when the completion of a task relies on a number of actions to occur in succession, 
officers have the capability to expedite the series of actions to complete the necessary steps more efficiently. For two primary reasons, officers responding to calls for service represent a key operational impact measure for large-bandwidth data communications. First, on average, patrol officers spend the majority of their time engaged in directed and self-initiated patrol (Wilson \& Weiss, 2012). If the implementation of a new technology is believed to enhance operations, it is best served targeting the operations to which officers allocate a significant amount of their time. Second, handling calls for service relies on the completion of multiple activities in succession (International Association of Chiefs of Police, 2005). Generally speaking, during a call for service an officer must go through a variety of checks to clear the call. Each of these actions relies on a previous action to be completed prior to progressing the process closer to completion. If each action, or step in the process, is expedited, the entire process of clearing a call for service is improved upon.

To construct an outcome variable of call clearance time, data were extracted from the police department's Computer-Aided Dispatch (CAD) system for all 269,425 CAD service calls received by the department for the years 2003 through 2009. Considered to be the most accurate and efficient means by which police patrol activities can be measured (Bureau of Justice Assistance, 2006), CAD systems are designed to capture a timestamp at which a call for service is communicated to a patrol officer as well as a timestamp at the point a patrol officer indicates the call for service has been completed. This entire process is automated and captured through the CAD system. The difference between these two timestamps is internally used by the department to self-assess call clearance times and inform resource allocation determinations to 
improve service efficiency ${ }^{3}$. As such, this measure represents the aspect of police operations most likely to be impacted by wireless broadband.

Call clearance times are provided in seconds. Data were received in aggregated form and were stratified by year and patrol sector, which creates a balanced abbreviated pooled time series of repeated average call clearance times for all nine of the department's patrol sectors across seven years. The choice to focus on patrol sectors was driven by the police department's procurement decision; one of the primary objectives of investing in a wireless broadband system was to remedy weak communication coverage issues among specific patrol sectors with significant terrain challenges. A total of 63 observations were used for analysis.

\section{Measurement of Predictors}

Pooled time series data allows for a retrospective quasi-experimental examination of the effect of wireless broadband implementation on call clearance time. The wireless broadband network was deployed department-wide October 1, 2006. As a precaution against unobserved implementation delays and to provide conservative estimates, the pre-implementation period was defined as the years 2003 through 2006. Post-implementation was defined as the years 2007 through 2009. Since the emphasis is on the relative effect of the implementation, the postimplementation period is specified as a dummy variable (1) and is compared to the preimplementation comparison period (0). In an effort to control variability in call clearance times

\footnotetext{
${ }^{3}$ CAD systems and data are complex and are uniquely suited to a specific agency (Wilson \& Weiss, 2012). As such, it is important to provide context on how the CAD system functions for the police department used for this study to offer insights on what the system does and does not capture. The system consists of 260 separate call codes for service and is basic in the sense of being strictly focused on service calls. The vast majority of calls for service are generated from dispatch. Officers may self-initiate service calls in the CAD system, but these occurrences are rare (Chief Technology Information Officer, personal communication, February 4, 2014). There are no separate "flags" or indicators in the CAD system that would differentiate dispatched calls from self-initiated calls. Information on two-officer patrol units, back-up officer units, and simultaneous dispatching are not captured by the CAD system. The CAD system does not possess call codes for report writing. Each call is entered as being cleared once the onscene work has been completed by the responding officer.
} 
that may be influenced by differences between patrol sectors as well as yearly fluctuations in the number of calls received a measure of total calls is used. This variable represents the number of calls received by year and patrol sector. Finally, a measure of weak signal is used to examine whether there were any differential effects between patrol sectors with historical cellular coverage issues (1) and sectors where there were few, if any, problems with communication coverage (0). Weak signal sectors were identified by the vendor providing the service through periodic diagnostic testing. These areas were documented by the police department for purposes of monitoring connectivity. Officer complaints in these weak signal areas were also an indicator of poor connectivity. Of the nine patrol sectors covered by the police department, four experienced ongoing issues with pre-implementation cellular communication systems.

\section{Data Analysis}

Mean bivariate difference tests were used to examine the relative influence of the predictors irrespective of patrol sector and year conditions. Central to these analyses is a baseline determination of whether wireless broadband implementation was associated with reductions in call clearance times. A secondary focus is on the association across the remaining predictors and call clearance times. Given the natural function and correlation between call clearance times and total calls $[r(63)=.24, \mathrm{p}<.05]$, relationships between predictors and total calls are also presented to provide context. Mean tests were conducted with the use of generalized analysis of variance (ANOVA) techniques.

Multivariate models for the abbreviated pooled time series control for variation that exists within and between patrol sectors and years. Models are estimated in an iterative stepwise fashion, with the introduction of each individual predictor until a fully conditional model is 
estimated. An interaction term is entered into the final model. This term represents the interaction of the post-implementation period among patrol sectors who had previously experienced issues with communication coverage (i.e., post-implementation*weak signal). This allows for the observation of the effect of implementation among patrol sectors with communication difficulties.

Generalized least squares random effect models were used. Breusch-Pagan Lagrange multiplier test indicated significant panel effects within the data, which negates the application of ordinary least squares estimations. Moreover, Hausman specification tests indicated that conditional models should be estimated with random rather than fixed effects. Robust standard errors were estimated to minimize heteroskedasticity and autocorrelation disturbances. Call clearance time and total calls were transformed into z-scores in the multivariate analyses to standardize observations.

\section{Findings}

Table 2 displays results from the mean difference tests. Significant differences in call clearance times were observed by patrol sector, year, and quasi-experimental condition. Average call clearance times varied from 200 seconds (Sector Four) to 325 seconds (Sector Nine). Perhaps aiding the explanation of this less-than intuitive average is that in the department of study, report writing is not included as part of the call clearance process. Reporting is a subsequent action and, as noted by Wilson and Weiss (2012), is not unusual in departments across the country. Yearly call clearance time averages ranged between 223 seconds in 2008 to 314 seconds in 2005 and were slightly higher prior to 2006. Results from the pre- and postimplementation periods confirm this trend. On average, call clearance times were 46 seconds 
faster in the post-implementation period. Weak signal sectors had longer call clearance times on average relative to strong signal sectors, but these differences were not statistically dependable.

Calls for service analyses are useful in the interpretation of the bivariate findings. Patrol sectors managed significantly different call volumes. This is to be expected and may have contributed to call clearance time results. At the high end, Sector Four averaged 8,538 calls with an average call clearance time of 200 seconds. This can be contrasted with Sector Six that averaged just over one-tenth the call volume as Sector Four and averaged a call clearance time one minute and nine seconds longer than Sector Four. Weak signal sectors managed over oneand-a-half times more calls than strong signal sectors.

Equally important are the non-significant bivariate findings for calls for service. There were no significant differences in calls fielded neither across years nor in the average amount of calls fielded during the pre- and post-implementation periods. The significant differences in call clearance time by year and pre/post conditions were observed despite relatively constant calls for service.

[ Table 2 approximately here ]

Random effect pooled time series multivariate analyses were conducted to take advantage and model the random variation across patrol sectors and yearly variation within each patrol sector. Table 3 presents the results. Overall, the post-implementation period was negatively associated with clearance times. Implementation was associated with a .68 standard deviation 
reduction ${ }^{4}$. This translates to a 39 second decrease in average call clearance times between patrol sectors over time $[(-.68 \times 57.80)+270.81=231.51]$. In the fully conditional model that includes an interaction term, a .78 standard deviation reduction in call clearance time was observed holding all other predictors constant. Average call clearance times decreased by 45 seconds after implementation $[(-.78 \times 57.80)+270.81=225.73]$.

None of the remaining predictors were significantly related to call clearance times. Directional trends suggest reductions in call clearance times between patrol sectors over time when total calls increase. A similar negative trend was observed for weak signal sectors. The interaction term indicated no differential effects of wireless broadband implementation within weak signal sectors relative to strong coverage sectors in pre- and post-implementation periods. In fact, the estimated coefficient suggests a slight increase in call clearance times among sectors with weak signals relative to strong signal sectors after implementation. To verify this result, supplemental models were estimated using a series of interaction terms interchanging weak and strong signal sectors with quasi-experimental conditions. None of these combinations provided support for differential effects.

[Table 3 approximately here ]

\section{Conclusions}

This research explored the effect of wireless broadband implementation on police clearance time of calls for service for one medium-sized municipal police department that was able to implement a dedicated wireless broadband network for public safety through a public-

\footnotetext{
${ }^{4}$ The Hausman test for the first iteration rejected the null hypothesis that the random effects estimator was consistent, which indicates that a fixed effect model may provide a better fit to the data. This is due to simplistic model specification, as only one predictor is used to generate an unconditional bivariate model. This first iteration was re-estimated as a fixed effect model with robust standard errors and produced a similar estimated result $(b=$ $.68, R S E=.28 \mathrm{p}<.05)$.
} 
private partnership. Pre- and post-implementation call clearance times for calls for service were examined with the use of a retrospective quasi-experimental design of abbreviated pooled panel data. The findings offer tentative support to the assertion that wireless broadband implementation improves police operations by reducing average call clearance times.

With ongoing discussions and legislative movement towards the development of a nationwide wireless network for public safety (see White House Briefing, 2011), this research offers a useful starting point to explore the potential benefits and implications of emerging wireless broadband communications capabilities. As one of the first attempts to empirically examine the movement towards wireless innovations and infrastructures, it is important to interpret these initial findings with caution. The benefit of reductions in call clearance times with broadband wireless implementation did not appear to be an artifact of chance; meaning the statistical likelihood of this association is highly probable. Yet, the substantive significance of these findings was relatively small. A 39 to 45 second decrease in annual call clearance times among patrol sectors was observed after implementation. While it is a commonly held truism that seconds matter in public safety, decisions to procure wireless broadband communication systems must consider whether such levels of reduction are sufficient.

It is important to recall that one of the motivations to implement wireless broadband among administrators of the police department was to remedy weak signal strength of prior communication systems in specific patrol sectors. The findings fail to offer support of any differential effects in call clearance times by signal strength and pre- and post-implementation periods. Wireless broadband did not appear to offer added benefit to operations in these sectors above and beyond the experiences of other sectors. While a direct test of pre- and postimplementation signal strength changes could not be conducted due to the retrospective nature of 
this research, the null findings do beg some questions about the efficacy of wireless broadband solutions to resolve signal issues and affect operations.

Efforts to examine and determine the relative effectiveness of technology are challenging and this research is no different. It is important to consider the findings with some limitations in mind. This research capitalized upon a quasi-experimental pre-post longitudinal design which increases rigor and confidence in the interpretation of findings over non-experimental and oneshot case study designs. However, the retrospective design negates the ability to utilize an experimental design with randomization of patrol sectors to wireless broadband or non-wireless broadband conditions. In addition, the design lacks a pure control group of units who were not exposed to wireless broadband implementation as the system was deployed department-wide. As a result, threats to the internal validity of the results cannot be completely ruled out.

The potential for rival hypotheses to affect and explain results is a common issue for applied research and evaluations using quasi-experimental designs (see Cook \& Campbell, 1979). Recent scholarship has advocated for the use of quasi-experimental designs in applied settings, noting that oftentimes such designs are the most feasible (Blumstein, 2013). This is especially true in law enforcement and public safety, where the structure and nature of operations and administrative objectives are not always in line with an ideal research design and data collection strategy (Braga, 2010). Indeed, the use of an experimental design for this study would limit rival hypotheses but also create increased expenditures and consumption of resources for the police department and city sponsoring this research.

While computer-aided dispatch data is unobtrusive and lacks reactivity concerns due to its automated collection of call clearance times, Sherman and Weisburd (1995) have noted these data can potentially be misleading as a result of internal policy changes. Ongoing discussions 
with administrators at the police department suggested no major changes to departmental polices, practices, or procedures across study years that would have impacted how computer-aided dispatch data were collected and tabulated. Bivariate findings provide some evidence to confirm these anecdotal conversations. There did not appear to be dramatic increases or decreases in calls for service across years. However it is not clear if policies about the process of responding to calls had changed. Supplemental analyses introduced dummy variables for patrol sectors and years in an attempt to control for unknown changes between and within sectors and years in random effect pooled time series models with and without autoregressive adjustments. Across all of these analyses, there were no substantive differences in the coefficients estimated in these supplemental models versus the primary results. Secondary data were also requested to examine changes in call types in pre- and post-implementation periods, which may be masked by the use of total calls for service. A subsample of data on high priority CAD call codes and a subsample of data on the most frequently occurring CAD call codes across study years (i.e., medical emergency, building check, and residential alarm) were received. Bivariate mean difference tests failed to show consistent post-implementation changes in the volume or clearance times associated with these calls for service. History and instrumentation threats may be plausible. Changes in lower priority call types, which are not among the most frequent call types processed by the department, are also potential unobserved threats. However, the combination of these supplemental analyses indicates that the net influence of these threats is unlikely to change the overall findings.

Often CAD systems do not identify specific instances that can influence call volume and clearance times, such as an officer not indicating when a call is completed or the presence of back-up personnel for assistance (Wilson \& Weiss, 2012). CAD systems generally are unable to 
differentiate dispatched calls for service from officer-initiated service activities (Wilson \& Weiss, 2012). The CAD system used by the police department for this research suffers from these very same challenges. The system does not identify or differentiate such instances and therefore contains an unobservable amount of measurement error that could not be controlled. It is presumed that the level of measurement error is relatively constant across the longitudinal panel of data. If measurement error is non-constant across the period of observation, extreme outliers and abnormalities within the data should be observed across years and patrol sectors. Such patterns were not observed in the data. Additionally, the rate of officer-initiated calls is estimated to be very small (Chief Information Technology Officer, personal communication, February 4, 2014).

The unique private-public partnership that was developed for the study site may be difficult to develop for municipalities across the United States, which limits the generalizability of this research. Wireless broadband implementation was a tangible reality for the study site, especially given the city's high socioeconomic standing, large proportion of highly educated citizen base, and low levels of violent crime. Such demographics are correlated with less-serious calls for service which could also enhance the utilization of wireless broadband for clearing service calls. The community-driven financial business model which made implementation possible relied on a client base which can both demand and afford a wireless capability. A commercial carrier is less likely to enter into such a partnership if they believe the population of an area will not allow them to generate positive earnings. Further complicating these efforts across the U.S. is the still-to-be-determined status of public safety spectrum for large bandwidth communications. Since wireless networks require hardware infrastructure conducive to a specific sector of spectrum (i.e., $700 \mathrm{MHz}$ versus $4.9 \mathrm{GHz}$ ) and that the system must be approved by the 
Federal Communications Commission, municipalities are likely to be hesitant to commit to such technology without the assistance of a public-private partnership. The ability to form such partnerships may be especially problematic for suburban and rural jurisdictions.

\section{Considerations for Future Research}

The present study has provided a foundation to advance evaluations of wireless broadband communication systems in policing and public safety. Much more research is needed to further explore the potential effects of wireless broadband on police operations. A number of lessons learned through this research can be expanded and elaborated in future work. First, it will be highly beneficial to identify and partner with agencies seeking to implement wireless broadband capabilities and work with these agencies prior to procurement of the technology. Such a partnership will position the agency and researchers for optimal success. Researchers will be able to capture information during the procurement decision-making process, develop an understanding of business models, and observe the necessary steps taken by an agency to implement the technology. A focus on process will inform agency administrators who seek answers on options for procurement and the necessary steps others take to obtain and implement new technologies. From a research design perspective, this approach will allow for the use of experimental or quasi-experimental designs with baseline comparison groups. Given the substantial resource investment that is typically associated with technological innovations within state and municipal government, the use of rigorous research designs are essential.

Second, it will be important to remember that any technological innovation is simply a tool to meet general or specific objectives. The efficiency or effectiveness of technology will be contingent upon users and their interactions with a new or emerging technology. A major 
challenge of technology evaluations is to specifically target the technical capability it provides, rather than the operations it enables. There is an inherent difference between the two. For example, an officer using mobile computing without wireless broadband would not be able to access and stream videos from the training lieutenant. Conversely, an officer using mobile computing without wireless broadband would still be able to fill in an automated field report. Attention to, and measurement of, technological capabilities are needed to improve the body of knowledge on efficiency and effectiveness. A body of work on human factors engineering would be beneficial to integrate into the process portions of future evaluations to understand how users interact with new technologies and how these relationships can shape relevant outcomes (see Salvendy, 2012).

Finally, the field will need to continue to develop a variety of robust measures of operational outcomes that can be observed before and after implementation. The Government Accountability Office (2012) recently noted that "data limitations make it difficult to fully measure the effect of expanding access to and adoption of broadband” (p. 12). Measures need to be unique to the technology being evaluated, but also identified in a manner that allows for direct observation or collection and ease of extraction if necessary. This is a difficulty that presents itself with reliance upon CAD data and management information systems. While the current research has demonstrated relationships associated with call clearance times, this is one of many measures that can be used to operationalize police operations. Future research should build from this work and seek to include multiple outcome measures. Aside from benefits of expediting the succession of events to clear calls for service, future research should attempt to identify criterion measures related to the quality of information flow and exchange as well as officer safety. It seems plausible that patrol officers could utilize higher quality information to improve decision 
making prior to encountering a citizen as well as during this interaction. Such improved information could lead to improved effectiveness and efficiency of interactions. Clearance rates, time spent on daily activities across all personnel levels, call priority types, productivity, and the consumption of capital expenditures are additional outcomes that could be examined across different levels of analysis.

While there is still much room for improvement, the results of this study do suggest that wireless broadband implementation can affect average call clearance times. It will be necessary to replicate and expand these findings to inform procurement, legislation, and policy decisions. The always-looming pressure for police to perform more efficiently and effectively will force the continued implementation of technologies which must be empirically assessed to guide future decisions. A policing research agenda that accomplishes these objectives and keeps pace with changing technological innovations is sorely needed. The findings presented here are a step in this direction. 


\section{References}

Agrawal, M., Rao, H. R., \& Sanders, G. L. (2003). Impact of mobile computing terminals in police work. Journal of Organizational Computing and Electronic Commerce, 13(2), 7389.

Amaldi, E., Capone, A., Cesana, M., Filippini, I. \& Malucelli, F. (2008). Optimization models and methods for planning wireless mesh networks. Computer Networks, 52(11), 21592171.

Blumstein, A. (2013). Linking evidence and criminal justice policy. Criminology \& Public Policy, 12(4), 721-730.

Braga, A. A. (2010). Setting a higher standard for the evaluation of problem-oriented policing initiatives, Criminology \& Public Policy, 9(1), 173-182.

Braga, A. A. \& Weisburd, D. L. (2006). Police innovation and the future of policing. In Police Innovation: Contrasting Perspectives (pp. 339-352). New York: Cambridge University Press.

Bureau of Justice Assistance. (2006). Standard functionalsSpecifications for law enforcement computer aided dispatch (CAD) systems. Washington, DC: U.S. Department of Justice.

Carter, D. L. \& Carter, J. G. (2009a). The intelligence fusion process for state, local and tribal law enforcement. Criminal Justice and Behavior, 36(12), 1323-1339.

Carter, D. L. \& Carter, J. G. (2009b). Intelligence-led policing: Conceptual considerations for public policy. Criminal Justice Policy Review, 20(3), 310-325.

Chan, J. B. L. (2001). The technological game: How information technology is transforming police practice. Criminology and Criminal Justice, 1(2), 139-159.

Chandra, A., Bose, C., \& Bose, M. K. (2011). Wireless relays for next generation broadband networks. Potentials, 30(2), 39-43.

Chenoweth, E. \& Clarke, S. E. (2010). All terrorism is local: Resources, nested institutions, and governance for urban homeland security in the American federal system. Political Research Quarterly, 63(3), 495-507.

Colvin, C. A. \& Goh, A. (2005). Validation of the technology acceptance model for police. Journal of Criminal Justice, 33, 89-95.

Cook, T. D. \& Campbell, D. T. (1979). Quasi-experimentation: Design and analysis issues for field settings. Boston, MA: Houghton Mifflin. 
ENCOM Wireless. (2010). Cellular “data crunch” leaves cities needing dedicated wireless network options. IMSA Journal, 48(1), 34-39.

Federal Bureau of Investigation. (2012). Uniform crime report: Crime in the U.S. Washington, DC: Federal Bureau of Investigation.

Garicano, L. \& Heaton, P. (2010). Information technology, organization, and productivity in the public sector: Evidence from police departments. Journal of Labor Economics, 28(1), 167-201.

Goldstein, H. (2003). On further developing problem-oriented policing: The most critical need, the major impediments, and a proposal. Crime Prevention Studies, 15, $13-47$.

Hampton, P. \& Langham, M. (2005). A contextual study of police car telematics: The future of in-car information systems. Ergonomics, 48(2), 109-118.

Harper, R. R. (1991). The computer game: Detectives, suspects, and technology. British Journal of Criminology, 31(3), 292-307.

International Association of Chiefs of Police. (2005). Pittsburgh Bureau of Police: Patrol staffing and deployment requirements. Phase 2 report. Alexandria, VA: International Association of Chiefs of Police.

Ioimo, R. E. \& Aronson, J. E. (2004). Police field mobile computing: Applying the theory of task-technology fit. Police Quarterly, 7(4), 403-428.

Kennedy, L. W., Caplan, J. M. \& Piza, E. (2011). Risk clusters, hotspots, and spatial intelligence. Risk terrain modeling as an algorithm for police resource allocation strategies. Journal of Quantitative Criminology, 27(3), 339-362.

Koper, C. S., Taylor, B. G., \& Kubu, B. E. (2009). Law enforcement technology needs assessment: Future technologies to address the operational needs of law enforcement. Washington, DC: Police Executive Research Forum.

Leonard-Barton, D. A., \& Deschamps, I. (1988). Managerial influences in the implementation of new technology. Management Science, 34(10), 1252-1265.

Lia, X. J., Seet, B. C., \& Chong, P. H. (2008). Multihop cellular networks: Technology and economics. Computer Networks, 52(9), 1825-1837.

Lindsay, R., Jackson, T. W. \& Cooke, L. (2013). Empirical evaluation of a technology acceptance model for mobile policing. Police Practice and Research. Online First. DOI:10.1080/15614263.2013.829602. 
Maguire, E. R. \& King, W. R. (2004). Trends in the policing industry. Annals of the American Academy of Political and Social Science, 593, 15-41.

Manning, P. K. (2001). Technology's ways: Information technology, crime analysis and the rationalizing of policing. Criminology and Criminal Justice, 1(1), 83-103.

Marina, M. K., Dasb, S. R. \& Subramanianb, A. P. (2010). A topology control approach for utilizing multiple channels in multi-radio wireless mesh networks. Computer Networks, 54(2), 241-256.

Moore, G. C., \& Benbasat, I. (1992). An empirical examination of a model of the factors affecting utilization of information technology end users. [White paper]. Vancouver, British Columbia, Canada: University of British Columbia.

Nunn, S. (2001). Police technology in cities: Changes and challenges. Technology in Society, 23, $11-27$.

Nunn, S. \& Quinet, K. (2002). Evaluating the effects of information technology on problem oriented-policing: If it doesn't fit, must we quit? Evaluation Review, 26(1), 81-108.

Police Executive Research Forum. (2012). How are innovations in technology transforming policing? Washington, D.C.: Police Executive Research Forum.

Ratcliffe, J. H. (2008). Intelligence-led policing. Cullompton, UK: Willan Publishing.

Reaves, B. A. (2010). Local police departments, 2007 (NCJ 231174). Washington, DC: Bureau of Justice Statistics.

Roberts, D. J. (2011). Technology is playing an expanding role in policing. The Police Chief, 78, 72-73.

Salvendy, G. (2012). Handbook of human factors and ergonomics ( $4^{\text {th }}$ ed.). Hoboken, NJ: John Wiley and Sons.

Seddon, P., \& Kiew, M. (1995, August). A partial test and development of the DeLone and McLean model of IS success. Paper presented at the International Conference on Information Systems. Vancouver, Canada.

Sharma, V. \& Jain, R.C. (2010). Multi-hop cellular networks: A review. International Journal of Engineering Science and Technology, 2(11), 6082-6091.

Sherman, L. W. \& Weisburd, D. (1995). General deterrent effects of police patrol in crime "hot spots”: A randomized, controlled trial. Justice Quarterly, 12(4), 625-648. 
Skogan, W. G., Hartnett, S. M., DuBois, J., Bennis, J., Kim, S. Y., Rosenbaum, D. P., Graziano, L. \& Stephens, C. (2003). Policing smarter through IT: Learning from Chicago's Citizen and Law Enforcement Analysis and Reporting (CLEAR) system. Washington, DC: Office for Community Oriented Policing Services.

Sprint. (2007). Mobile broadband solutions for the changing workplace in federal, state and local government. Kansas City, KS. Sprint Nextel.

Taylor, M. J., Epper, R. C., \& Tolman, T. K. (1998). Wireless communications and interoperability among state and local law enforcement agencies. Washington, DC: National Institute of Justice.

Taylor, R. W. \& Russell, A. L. (2012). The failure of police ‘fusion’ centers and the concept of a national intelligence sharing plan. Police Practice and Research, 13(2): 184-200.

U.S. Census Bureau. (2012). Income, poverty, and health insurance coverage in the United States: 2012. Washington, DC:

U.S. Government Accountability Office. (2012). Broadband programs Are ongoing, and agencies' efforts would benefit from improved data quality. A report to Congressional Committees. Washington, DC: U.S. Government Accountability Office.

Webb, M. (2004). Wireless standards to enable broadband. The Police Chief, 71, 6.

White House Briefing. (2011). The benefits of transitioning to a national wireless broadband network for public safety. Washington, DC: The White House.

Wilson, J. M. \& Weiss, A. (2012). A performance-based approach to police staffing and allocation. Washington, DC: Office of Community Oriented Policing Services. 


\section{Tables}

Table 1. City of study crime compared to national averages in 2012

\begin{tabular}{lccc}
\hline & City of Study & $\begin{array}{c}\text { National Population } \\
25,000-49,999\end{array}$ & $\begin{array}{c}\text { National Population } \\
50,000-99,999\end{array}$ \\
\hline Property Crime & 148 & 207 & 458 \\
Burglary & 637 & 746 & 1,479 \\
Larceny & 18 & 56 & 161 \\
Motor Vehicle Theft & 0 & 5 & 12 \\
Arson & 803 & 1,014 & 2,110 \\
Total & & & \\
Violent Crime & 0 & 1 & 2 \\
Murder & 4 & 9 & 18 \\
Forcible Rape & 31 & 28 & 74 \\
Robbery & 47 & 66 & 153 \\
Aggravated Assault & 82 & 104 & 247 \\
Total & & & \\
\hline
\end{tabular}

Source: 2012 Uniform Crime Report data (Federal Bureau of Investigation, 2012) 
Table 2. Descriptive statistics summarized by calls for service and call clearance times ( $\mathrm{N}=63$ )

\begin{tabular}{|c|c|c|}
\hline & Total Calls & Call Clearance Time \\
\hline \multicolumn{3}{|c|}{ Patrol Sector } \\
\hline 1 & 6010.43 (472.53) & $296.86(47.17)$ \\
\hline 2 & $5174.43(430.16)$ & $268.71(22.31)$ \\
\hline 3 & 4131.14 (439.28) & 303.43 (34.03) \\
\hline 4 & 8538.43 (406.63) & $200.43(30.24)$ \\
\hline 5 & 4651.28 (406.63) & $253.00(41.41)$ \\
\hline 6 & $977.71(428.36)$ & $268.71(87.56)$ \\
\hline 7 & 1530.28 (627.36) & $276.57(56.40)$ \\
\hline 8 & 1906.57 (148.40) & $244.86(30.04)$ \\
\hline 9 & 2236.00 (343.35) & 324.71 (60.09) \\
\hline Test & $F(8,54)=209.71^{* * *}$ & $F(8,54)=3.79 * * *$ \\
\hline \multicolumn{3}{|l|}{ Year } \\
\hline 2003 & 3750.89 (2401.29) & 300.89 (77.71) \\
\hline 2004 & 3779.44 (2610.63) & $275.78(56.01)$ \\
\hline 2005 & 4307.55 (2605.68) & 313.89 (63.31) \\
\hline 2006 & 3982.22 (2631.94) & 277.33 (61.85) \\
\hline 2007 & 4065.78 (2482.26) & 262.44 (28.18) \\
\hline 2008 & $4043.11(2344.04)$ & 223.11 (24.46) \\
\hline 2009 & 3414.78 (2417.50) & $242.22(27.42)$ \\
\hline Test & $F(6,56)=.12$ & $F(6,56)=3.28^{* *}$ \\
\hline \multicolumn{3}{|c|}{ Implementation } \\
\hline Pre & 3945.96 (2455.28) & 296.85 (65.70) \\
\hline Post & 3876.47 (2378.55) & 251.28 (42.38) \\
\hline Test & $F(1,61)=.01$ & $F(1,61)=11 \cdot 16^{* * *}$ \\
\hline \multicolumn{3}{|c|}{ Coverage } \\
\hline Weak & 4694.60 (2488.23) & 285.75 (56.03) \\
\hline Strong & 2920.82 (1879.51) & 258.86 (57.17) \\
\hline Test & $F(1,61)=9.76^{* *}$ & $F(1,61)=3.50$ \\
\hline Overall & 3906.25 (2392.27) & $270.81(57.80)$ \\
\hline
\end{tabular}


Table 3. Random effects pooled time series regression of standardized call clearance times by implementation with robust standard errors $(n=63)$

\begin{tabular}{lcccc}
\hline & $\mathrm{b}(\mathrm{RSE})$ & $\mathrm{b}(\mathrm{RSE})$ & $\mathrm{b}(\mathrm{RSE})$ & $\mathrm{b}(\mathrm{RSE})$ \\
\hline & & & & \\
Post-Implementation & $-.68(.28)^{* *}$ & $-.69(.28)^{* *}$ & $-.69(.28)^{* *}$ & $-.78(.32)^{* *}$ \\
Total Calls (z) & & $-.15(.20)$ & $-.08(.18)$ & $-.08(.17)$ \\
Weak Signal & & & $-.34(.29)$ & $-.44(.49)$ \\
Post-Imp*Weak Signal & & & & $.17(.54)$ \\
& & & & \\
Constant & $.59(.30)^{*}$ & $.59(.27)^{*}$ & $.44(.27)$ & $.84(.40)$ \\
& & & & \\
& & & & $11.16^{* * *}$ \\
\hline Breusch-Pagan Lagrange & $20.50^{* * *}$ & $12.86^{* * *}$ & $12.28^{* * *}$ \\
Multipler test & & & & \\
Hausman test & $5.92^{*}$ & 2.02 & 1.68 & 1.82 \\
Model chi-square (Wald) & $5.92^{* *}$ & $11.44^{* *}$ & $10.43^{* *}$ & $10.00^{*}$ \\
df & 1 & 2 & 3 & 4 \\
R-square & .01 & .23 & .24 & .24 \\
\hline Sigma u & .48 & .46 & .48 & .48 \\
Sigma e & .65 & .65 & .65 & .66 \\
Theta & .55 & .53 & .54 & .54 \\
Rho & .36 & .33 & .35 & .35 \\
\hline
\end{tabular}

${ }^{*} p<.05,{ }^{* *} p<.01,{ }^{* * *} p<.001$ 